\title{
Research on seismic behaviour of composite Steel concrete moment frames
}

\author{
Bhavesh Joshi Shahnawaz Ansari, Abhishek Sharma, Shailendra Kumar and Pratheek Sudhakaran
}

†First author's Department, First-Author University, Address Including Country Name

*Second author's Department, Second Author University, Address Including Country Name

Received 01 Jan 2018, Accepted 04 March 2018, Available online 07 March 2018, Vol.8, No.2 (March/April 2018)

\begin{abstract}
Most experimental research on composite steel concrete moment frames corresponds to situations of vertical loading. Under horizontal loading like earthquakes, positive bending moments can appear at the beam ends. To solve seismic design issues, a research effort has been promoted by the European Union. It involves experimental activity in several large European testing installations which are described and numerical model studies.
\end{abstract}

Keywords: Steel reinforcement, concrete, beam, slab \& column

\section{Introduction}

Until recently, the seismic design of composite steel concrete structures was leaving the designer in front of many questions for which no convincing answers or minimal guidance exist. The behavior of composite moment frames in recent earthquakes was sometimes bad. Some reasons are to be found on the steel material and welding side, but specific composite aspects of the elements and structures behavior probably contributed.

Composite constructions can correspond to many different structural typologies or systems, as long as concrete and steel are combined. The complete understanding of all aspects of the seismic behavior of all types of composite structure requires years of research efforts. Most developments in the U.S. have been bearing on composite moment frames with partial strength connections and on composite systems combining concrete walls or columns with steel or composite beams.

In India, since 1996, recent research work has been focused on moment frame structures with rigid connections. Important experimental and numerical modeling activities have been developed and are presented in the ICONS Report (Plumier 2001). These activities and the main results obtained are summarized here. The main practical outcomes for designers are presented in a companion paper (Plumier 2001).

*Corresponding author's ORCID ID: 0000-0002-7919-8405, DOI: https://doi.org/10.14741/ijcet/v.8.2.6
Cyclic tests on beam-column sub-assemblages at T.U.Darmstadt

Three full-size interior composite beam-to-column joint assemblies of a composite building frame with floor slabs were tested under cyclic loading. Several particular design concepts were considered, such as different layout and concentration of studs and reinforcements, and the influence of a transverse beam in the composite beam-to-column moment force transfer (Doneux 1998). The three sub-assemblages were replicas of parts of a 3D structure tested at JRC Ispra - ee next paragraph. The main goal of the research project was to study the role of the slab on moment transfer in earthquake resistant composite frames.

The main results of the tests are:

- The measures taken to maximize the effective width are effective.

- $\quad$ The design relations presented in (Plumier 1998) gave a safe design, bringing the intended yielding scheme for a value of bending moment which can rather accurately be computed. The positive plastic moments are as well estimated on the basis of the EC4 definition of effective width as on the basis of the Plumier's mechanisms (direct compression and inclined struts).

The negative plastic moments are underestimated on the basis of the old EC4 definition of effective width, but overestimated on the basis of the new EC4 definition of effective width.

The transverse beam is not really activated in the case of a rigid slab. This mechanism is too 
flexible in comparison with the high stiffness of the direct compression of the concrete on the column.

The behavior of the slab as a tension or compression flange of a beam carrying membrane forces is a complex phenomenon, which is deeper studied in a detailed non linear numerical model of the beam-column-slab connection zone-see paragraph 9 .

\section{Bi-directional cyclic testing of a 3-d frame at the JRC - ISPRA}

A test of a full-scale structure has been run in the ELSA reaction-wall facility of the European Joint Research Centre at Ispra, Italy (Bouwkamp 1998) (Plumier 1998) Figure 2 . The structure, a 3 storey 3 bay by 3 bay moment frame, has been conceived in order to test design hypothesis. It is an assembly of various zones characterised by variations of parameters like the density of devices connecting the slab to the beams, the density of the reinforcement of the slab, the proportions of the composite sections, the effectiveness of the stress transfer from the slab to the columns. From the test, moment rotation curves at every connection have been derived.

The following test program has been executed:

Cyclic loading in $\mathrm{X}$ direction and $\mathrm{Y}$ direction up to $2 \%$ drift; Y continued to $1 \%$ and $2 \%$ drift ;

pseudo Dynamic Test;

Cyclic loading in $\mathrm{X}$-direction until failure; max. topfloor displacement +/- $400 \mathrm{~mm}$ (4.5\%drift)

The main conclusions of the tests are:

The design relations of the reinforcements of the slab of composite beams gave a layout that maintained the intended integrity of the concrete during the cyclic testing.

The effective widths of slab deduced from Eurocode 4 [CEN, 1994] provide correct estimates of the real plastic moments of composite beams.

Paulay's definition of effective width gives slightly better results for capacity design. the plastic moments must be computed taking into account all the re-bars present, welded mesh and simple re-bars.

Considering the steel sections only in the design of composite frames is totally inaccurate; it is also unsafe for what concerns the capacity design of columns.

Disconnecting the slab from the beams ends and from the columns in a narrow zone does not prevent bending moments higher than those of the steel sections to be realised in the plastic hinges.

The global structure overstrength of the structure has been assessed on the basis of the global base shear - top displacement curves of test phase 1 and 5; the over strength is the ratio of maximum resistance to first yield load: $\alpha \max / \alpha 1=2400 / 1100=2.2$
Considering that failure is reached after a resistance drop of $20 \%$ of the maximal load, a reliable structural over strength is: $\alpha u / \alpha 1=0.82400 / 1100=1.75$ Numerical studies have also been performed.

Beam to-column connection zones at either end of the beams were modelled with DRAIN-2D as linearnon-linear fibre models capable of representing the non-linear cyclic response of the composite beams in those regions. Columns and beams were modelled as steel and, respectively, composite linear beam-column elements.

Numerical results show agreement with the experimental results. Considering the test performance of the 3-D frame and this correlation with numerical results, the composite moment resistant structure would perform well under an actual design earthquake. In fact, using the Ballio method to determine the behaviour factor $\mathrm{q}$, the results for the test frame with a thickness of the slab of $15 \mathrm{~cm}$, indicated a $q=4.5$.

\section{Dynamic tests on the ductility of composite beams at Bergamo}

In order to determine the condition to realise ductile composite steel-concrete section, three shaking table tests have been performed on composite steel-concrete simply supported beams at ISMES (now ENEL-HYDRO) in Bergamo, Italy (Plumier 1998). The composite sections were chosen to fail by concrete crushing. The ultimate deformation of the concrete $\varepsilon c u$, in dynamic cyclic conditions appears greater than the $2.10-3$ value given by Eurocode 2 for static design but smaller than the value of the static concrete test. The ductility ratio of the composite beams, based on the mid-span vertical deflections values, is greater than 3 . The relative sliding between steel and concrete brings a damping evaluated greater than $15 \%$ at high level of acceleration $\left(25-30 \mathrm{~m} / \mathrm{s}^{2}\right)$. A study on the influence of the degree of connection on damping is needed to calibrate this effect. The steel-deck shape can influence the failure mode and the ductility. A study involving various steel-deck shapes is needed to evaluate this influence and to eventually forbid some shapes.



Fig.1 The 3 D moment resistant frame tested at JRC Ispra 


\section{Shaking table tests on beam-column sub- assemblages at NTUA}

To evaluate the difference in responses between cyclic quasi static and real dynamic tests, beam-column subassemblages have been tested on the shaking table at the National Technical University at Athens, Greece. Two shear interactions have been considered. The tests also provided data on the low cycle fatigue resistance of the headed studs connecting the steel sections and the concrete: it was demonstrated that a the low cycle fatigue resistance may be the critical aspect of design once partial shear connection is realized. A 3 bay plane composite frame has been tested under constant amplitude of displacements at the CEA Saclay, France. The parameters considered are the degree of shear connection between steel and concrete and an original detailing of the connection between slab and facade steel beam.

\section{OW cycle fatigue test of a plane composite frame at CEA}

The test intended to set forward the peculiar aspects of behaviour of composite beams in low Cycle fatigue and to study the redistribution of bending moments during the applied force reversals as well as to provide the usual data on elastic stiffness and plastic resistances of beams of different design. The tests concluded to the following:

The bottom fibres of composite sections follow the same fatigue curve as the steel section used; however, given the higher strains at equal rotation in a composite beam with reference to a steel beam, the fatigue life is reduced by a factor of at least 2 .

The test has demonstrated the effectiveness of the anchorage of the re-bars to the studs of the external transverse beam, under negative bending, and of bearing of compression of the concrete on the transverse beam under positive bending;

As far as the inertia is concerned, the provisory beff proposed in the I CONS-EC8 1998 draft version overestimates the positive moment of inertia, but on the contrary, the beff proposed in the same document underestimates the negative moments of inertia;

These two results have to be considered to define the values of beff finally proposed for EC8; these ones should give the best possible estimate of the response of the structure, because in seismic design, lower bound values can be on the safe side for some aspects of the response and on the unsafe side for other aspects : typically safe side for resistance and unsafe side for displacements, meaning seismic forces and P-D effects. The Iequivalent, proposed by the ICONS-EC8 1998 document gives the best estimate of the moment distribution along the composite beam.

\section{Experimental evaluation of behaviour factors at Bristol}

A series of shaking table tests, realised at Bristol University, UK, (Tsujii 1999) have been dedicated to the experimental evaluation of behaviour factors of composite steel concrete structures made of partially encased sections without slab. A comparison of the composite frames with bare steel frames was conducted. This study, coupled with numerical dynamic analysis using the ADAPTIC software, came to the conclusion that behaviour factors of the composite frames were slightly larger than that of the bare steel frame, while higher values of overstrength and dynamic ductility were also observed. In parallel, other purely numerical work was also done in order to handle better the context of the behaviour factors of composite structures. In particular, a study was dedicated to the definition of the correct way to evaluate $\mathrm{q}$ factors, because it had appeared that in past studies many different definitions of such critical parameters as first yield or plastic redistribution factor had been used, sometimes bringing apparent high discrepancies in results, which in fact were only related to the methodology. (Sanchez 1999)

\section{Cyclic tests on connectors at Insa Rennes and TRENTO}

An extensive research work on headed studs and on cold-formed HILTI connectors has been realised at INSA Rennes, France (Aribert 2000) and at the University of Trento to provide data on the cyclic behaviour of the connectors.

\section{Analysis of composite beam to column connection behaviour}

The finite element program Castem 2000 developed at the CEA is used in the University of Liège to perform non-linear analysis of beam to column connection zone of composite moment frames with or without transverse beam.

The node and its loading are symmetrical and only one half a node is modelled using mostly 4 noded thin shells. The contact between the slab and the column, characterised by the possibility of separation under negative moment and contact under positive moment, is modeled by using unilateral conditions of support The material laws of the steel elements are either elastic, or elasto-plastic according to whether they are likely to enter the non-linear field or not. The yield criterion is Von Mises with isotropic hardening. Certain typical plates of the test rig are coarsely modelled using elastic 8 noded bricks. The loading is carried out by a horizontal imposed displacement at the top of the column. The slab is modelled with multi-layered thin shells, making it possible to take into account the flexural behaviour of the slab by the use of only one geometry with which is associated a set of layers in 
plane stress state. The layer of reinforcement is included in the same shell as the concrete with plastic one-directional material laws. The concrete model combines a Rankine fixed crack model for tension and an elastoplastic law with Drucker-Präger criteria for compression. Shear connectors are modelled by means of beam elements, connecting the higher flange of the beams and the neutral axis of the slab (its geometrical position). They are gauged on the basis of a shear force -slip law elastic perfectly plastic deduced from theoretical formulas. Equivalence is double: equivalent stiffness and equivalent resistance, given according to the number of modelled connectors compared to their real number. It is assumed that the strain profiles in the concrete and in the steel section are parallel, that means that there is no separation at steel/concrete interface and that the curvatures in each strain profile are the same. This assumption is translated in the model by equalising the rotations of the ends of the connectors A first step has been made to model typical beam-tocolumn steel-concrete composite nodes and results have been obtained.

The simple fixed crack model for the concrete in tension and the Drucker-Präger plasticity model for the concrete in compression have been used. A calibration of the parameters of the models has been made. Until now, the applicability of the model is not certain when strong degradation of concrete and yielding of steel take place at the top of the section, since the research work made and the experimental results are obtained in design options where the slab is not damaged and yielding takes place at the bottom part of the section. A certain confinement had to be taken into account in and around the column. Only this confinement and the accordingly increased ultimate strain can explain the plastic resistances observed. This is a first important result set forward by the numerical modelling presented here. The role of the transverse beam has been studied.

The conclusion is that its role is not as important as expected. This mechanism is more flexible than the direct compression of the slab on the column flange and the inclined compressive struts at the sides of the column. The need of deformability to activate a contribution of the transverse beam may be high so that crushing of concrete takes place before on the column face. Also, the possibility of transferring a force through a transverse beam working in non-uniform torsion without yielding the upper flange is small. The great plastic moment observed under positive bending moment is more due to confinement than to the presence of a transverse beam. Only specific design, like horizontal cantilever beams covering the full depth of the slab and directly fixed to the column, would realise an effective transverse beam mechanism.
A modelling isolating the cross beam mechanism in a beam-to-column joint without any direct compression of the slab on the column faces is realised to study this detail.

A complete study, considering different slab design, with different reinforcement ratio and different slab depth to beam depth ratio, is under way. It may require a better model for concrete, especially in tension; it is expected that a rotating crack model or even a plasticity model in tension would solve the over resistance problems and lead to better estimates of the ultimate loads.

\section{Acknowledgements}

The research activity presented has been developed with funding of DG III and DG XII of the European Commission, through the ICONS project (a research network financed by the TMR program) the ECOEST project (a Large Installation Network project) and the RECOS project(an INCO-COPERNICUS project).

\section{References}

Plumier (2001). ICONS Report 4. Composite Steel Concrete Structures. Laboratorio Nacional de Engenharia Civil Editor. Lisbon-Portugal.

Plumier, A and Doneux, C (2001), European developments of seismic design guidelines for composite steel concrete structures, Proceedings of ICSCS'01 Conference, Pusan, Korea Aribert, JM and Lachal, A, Moment resistant connections of steel frames in seismic areas,pp299-313, Mazzolani Editor, E.F.SPON, London

Bouwkamp, J., Parung, H. and Plumier, A. (1998), Bidirectional cyclic response study of a 3-D composite frame, Proceedings of the 11th ECEE Conference, Paris.

Doneux, C. and Parung, H. (1998) A study on composite beam-column subassemblages, Proceedings of the 11th ECEE Conference, Paris.

Doneux, C. and Plumier, A. (1999), Seismic design of the slab reinforcements of composite beams on moment frames, Internal Report for ICONS project, Université de Liège.

ICONS Topic 4 Extended Group (1998), Draft of a section Specific rules for steel concrete composite buildings, an ICONS project Report, Université de Liège.

Plumier, A., Doneux, C., Bouwkamp, J.G. and Plumier, C. (1998), Slab design in connection zones of composite frames, Proceedings of the 11th ECEE Conference, Paris.

Plumier, C. and Doneux, C. (1998) Dynamic tests on the ductility of composite steelconcrete beams, Proceedings of the 11th ECEE Conference, Paris.

Sanchez, L and Plumier, A. (1999), Particularities raised by the evaluation of load reduction factors for the seismic design of composite steel concrete structures, Proceedings of the SDSS'99 Stability and Ductility of Steel Structures Colloquium, Timisoara.

Tsujii, M., Elnashai, A.S. and Broderick, B. (1999), Experimental and analytical evaluation of behaviour factors for steel and composite frames, Internal Report for ICONS project, Imperial College London. 